\title{
Caudal regression-sirenomelia spectrum
}

INSERM

\section{Source}

INSERM. (1999). Orphanet: an online rare disease and orphan drug data base. Caudal regression-sirenomelia spectrum. ORPHA:444941

Caudal regression-sirenomelia spectrum is a group of rare genetic developmental defect during embryogenesis disorders characterized by varying degrees of caudal abdomen, pelvic, renal, anorectal, urogenital and/or lumbosacral spine malformations, with or without lower limb fusion. Phenotype is highly variable rang ing from minor forms with isolated coccygeal agenesis to severe forms presenting with a single rudimentary limb. Central nervous system anomalies have also been reported. 